\title{
MIGRACIÓN IRREGULAR Y AISLAMIENTO SOCIAL Los jornaleros tamaulipecos indocumentados en los Estados Unidos
}

\author{
IRREGULAR MIGRATION AND SOCIAL ISOLATION \\ Tamaulipas' Undocumented Farm Workers in the United States
}

\author{
Simón Pedro lzcara Palacios \\ Universidad Autónoma de Tamaulipas. México \\ sp_izcara@yahoo.com; sizcara@uat.edu.mx
}

\begin{abstract}
RESUMEN
El concepto de "aislamiento social" ha sido insuficientemente utilizado en el análisis de la pobreza. "Exclusión social" y "marginalidad" son dos conceptos más desarrollados. El "aislamiento social" hace referencia a una erosión de las esferas relacionales del individuo (esto es, a una falta de soporte familiar y/o redes sociales, y a una ausencia de actividad social e interacción recreacional). Más aún, el "aislamiento social" está asociado a síntomas de ansiedad y depresión. Este artículo analiza la situación de aislamiento social de los jornaleros indocumentados tamaulipecos empleados en los Estados Unidos.
\end{abstract}

\section{Palabras Clave}

Agricultura, Inmigración ilegal, Tamaulipas, Trabajadores rurales.

\footnotetext{
ABSTRACT

"Social isolation" is a concept poorly developed in the analysis of poverty. "Social exclusion" and "marginality" are concepts more frequently used. "Social isolation" refers to an erosion of the relational sphere of the individual (that is, it is a lack of familial support and/or social networks, and an absence of social activity and recreational interaction). Moreover, "social isolation" is associated with anxiety and depression symptoms. This paper analyses the situation of "social isolation" of Tamaulipas' undocumented farm workers employed in the United Stated.
}

\section{KEYWORDS}

Illegal Immigration, Farming, Tamaulipas, Rural Workers. 


\section{INTRODUCCIÓN ${ }^{1}$}

Tamaulipas, un estado situado en el noreste de México que comparte 370 kilómetros de frontera con Texas, presenta una larga tradición migratoria al país del norte. La experiencia de la población rural de Tamaulipas en actividades agrarias muy demandantes, como la pizca de cítricos o la zafra de la caña (Izcara Palacios y Andrade Rubio 2007: 66), ha ocasionado que por décadas la valía de los braceros tamaulipecos haya sido apreciada por los empresarios agrarios estadounidenses (Izcara Palacios 2006: 109). Los jornaleros tamaulipecos han emigrado principalmente de forma indocumentada; sin embargo, también han participado profusamente en los programas de trabajadores huéspedes implementados por Estados Unidos. Fueron muchos los trabajadores que participaron en el programa Bracero que se extendió desde 1942 hasta 1964; como son muchos los que participan en la actualidad. En el año 2006 tan sólo el Consulado de Estados Unidos en Monterrey aprobó 1.885 visas H-2A a trabajadores tamaulipecos, lo cual coloca a Tamaulipas como uno de los principales centros emisores de trabajadores huéspedes agrarios.

El Valle de Texas es la región de Estados Unidos más cercana a Tamaulipas, como consecuencia es la zona más accesible y la que tradicionalmente más inmigrantes tamaulipecos ha recibido. Además, esta área presenta lazos histórico-culturales muy angostamente trenzados con Tamaulipas (Spener 2001: 210). Sin embargo, las condiciones sociolaborales imperantes en la agricultura del sureste de Texas son especialmente severas. Los salarios son más bajos que en otras áreas del país y el problema del desempleo y subempleo son más acusados. Desde comienzos de siglo el mercado laboral agrario tejano apareció caracterizado por una mayor discriminación (Fonseca y Moreno 1988: 78), hasta el punto de que durante los años cuarenta el gobierno mexicano insistió reiteradamente en excluir los ranchos tejanos como destino de los jornaleros contratados en el marco del Programa Bracero (Gilbert 2005: 429).

En el contexto de una progresiva militarización de la frontera y de una mayor criminalización de la migración ilegal el atractivo de la agricultura del Valle de Texas ha disminuido. Actualmente, cuando el inmigrante tamaulipeco asume el riesgo de cruzar la frontera espera obtener un mayor retorno económico que el proporcionado por el mercado de trabajo fronterizo. Estos realizan desplazamientos cada vez más largos y sus estancias en el país vecino son también más prolongadas (Izcara Palacios 2009b: 26).

\footnotetext{
${ }^{1}$ Quisiera expresar mi agradecimiento tanto a Consejo Nacional de Ciencia y Tecnología (CONACYT, México) a través del proyecto "Migrantes estacionales de Tamaulipas en la agricultura de Estados Unidos", $N^{\circ}$ 52636, como a la Universidad Autónoma de Tamaulipas, a través del proyecto "Migrantes rurales tamaulipecos y el programa H-2A de trabajadores huéspedes". (Convenio número: UAT-07-8-SOC-0114), por el apoyo recibido para la realización de esta investigación.
} 
Los jornaleros tamaulipecos siguen dos rutas principales hacia el interior de los Estados Unidos. Una, la más importante, se desliza por el sureste estadounidense; pasa por Luisiana, Mississippi, Florida, Georgia, Tennessee, Carolina del Norte y llega hasta Virginia. La otra ramificación, de menor envergadura, llega hasta el centro-norte de los Estados Unidos; principalmente a Michigan y Minnesota. Florida es una de las zonas más apreciadas por los trabajadores rurales tamaulipecos indocumentados debido a los elevados salarios pagados en el sector citrícola y el elevado grado de aceptación de la mano de obra ilegal. Carolina del Norte es otra zona que ejerce una enorme atracción sobre la mano de obra rural tamaulipeca. Aunque los jornaleros de Tamaulipas no guardan un buen recuerdo de esta zona, donde son empleados principalmente en el tabaco, una actividad caracterizada por una alta morbilidad (Rao et al. 2002: 505). Virginia es un Estado del cual los tamaulipecos guardan un agradable recuerdo debido a los elevados salarios que obtienen en la pizca de la manzana, una actividad que requiere unas habilidades físicas y destrezas que ellos adquirieron en su lugar de origen. En ocasiones los jornaleros indocumentados tamaulipecos construyen un cordón migratorio que se desplaza de Florida a Virginia haciendo un intermedio en Carolina del Norte. Durante los meses de diciembre a abril hay trabajo abundante en Florida en la pizca de la naranja; desde abril hasta julio se extiende la temporada álgida de demanda de mano de obra en las plantaciones tabaqueras de Carolina del Norte, y entre septiembre y noviembre se incrementa la demanda de mano de obra en la pizca de la manzana en Virginia. Aquellos que se desplazan hacia el centro-norte, principalmente a Michigan y Minnesota, pero también hasta Dakota del Sur, encuentran especialmente duro soportar unas condiciones climáticas que divergen enormemente del clima tamaulipeco.

Este artículo se adentra en el análisis de la situación de aislamiento social de los migrantes rurales tamaulipecos indocumentados empleados en el sector agrario estadounidense.

\section{Metodología}

Esta investigación aparece cimentada en una metodología cualitativa. Un total de cincuenta trabajadores rurales tamaulipecos con experiencia de haber cruzado ilegalmente la frontera y haber sido empleados en la agricultura fueron entrevistados en más de 35 comunidades rurales de 13 municipios tamaulipecos representativos de la diversidad geográfica de este estado durante los meses de marzo de 2007 a junio de 2008. Se utilizó un muestreo estratificado intencional en función de dos variables: el género y la edad. Por una parte, se buscó que un $25 \%$ de los informantes fuesen mujeres ${ }^{2}$. Por

\footnotetext{
${ }^{2}$ Este porcentaje representa grosso modo la participación de la mujer en el mercado de trabajo agrario estadounidense (Mines et al. 1997; Mehta et al. 2000: 10; Carroll et al. 2005: 9).
} 
otra parte, se persiguió que un tercio de los informantes fuesen menores de 30 años de edad, otro tercio tuviesen edades comprendidas entre 30 y 45 años, y otro tercio fuesen mayores a 45 años. Con esta división por edades se pretendía subrayar el predominio de trabajadores jóvenes en esta actividad; pero al mismo tiempo se quería rescatar el testimonio de trabajadores de mayor edad que en décadas pasadas emigraron a Estados Unidos, con objeto de recuperar un dibujo diacrónico de la presencia de trabajadores tamaulipecos en la agricultura estadounidense (Cuadro 1).

\section{Cuadro 1.}

Códigos utilizados para identificar a los jornaleros entrevistados.

\begin{tabular}{|c|c|c|c|c|c|c|}
\hline \multirow[t]{2}{*}{ Código } & \multirow[t]{2}{*}{ Sexo } & \multirow[t]{2}{*}{ Edad } & \multicolumn{2}{|c|}{ Lugar de residencia } & \multicolumn{2}{|c|}{ Lugar de emigración } \\
\hline & & & Municipio & Localidad & Periodo & Estado \\
\hline A1 & Mujer & 28 & Aldama & La Colmena & $96 / 04$ & Nueva York \\
\hline A2 & Varón & 23 & Aldama & Barra del Tordo & $02 / 03$ & Georgia \\
\hline A3 & Varón & 60 & Aldama & El Barranco & $80 / 05$ & Oklahoma, Atlanta \\
\hline AM1 & Varón & 43 & Antiguo Morelos & La Loma & $78 / 82$ & Texas \\
\hline AM2 & Varón & 38 & Antiguo Morelos & México Libre & 85 & Texas \\
\hline B1 & Varón & 31 & Bustamante & Bustamante & $93 / 97$ & Luisiana, Florida Míchigan \\
\hline EM1 & Varón & 27 & El Mante & La Mora & $03 / 07$ & $\begin{array}{l}\text { Georgia, Alabama, Texas, } \\
\text { Florida }\end{array}$ \\
\hline EM2 & Varón & 33 & El Mante & Nueva Apolonia & 02 & Texas \\
\hline EM3 & Varón & 48 & El Mante & Benito Juárez & $90 / 93$ & Texas \\
\hline G1 & Varón & 34 & Guémez & Guémez & $98-07$ & Texas, Atlanta, Florida \\
\hline G2 & Varón & 34 & Guémez & Guadalupe Victoria & 07 & Texas \\
\hline H1 & Varón & 32 & Hidalgo & Santa Engracia & $97-03$ & Carolina N., Virginia, Florida \\
\hline J1 & Varón & 36 & Jaumave & El Sauz & 02/06 & $\begin{array}{l}\text { Texas, Carolina del Norte, } \\
\text { Virginia }\end{array}$ \\
\hline J2 & Mujer & 30 & Jaumave & La Reforma & $99 / 08$ & Texas \\
\hline J3 & Mujer & 45 & Jaumave & Palomas & $90 / 92$ & Texas \\
\hline J4 & Varón & 64 & Jaumave & Morelos & $74 / 08$ & Arkansas, Texas, Georgia \\
\hline J5 & Varón & 40 & Jaumave & La Reforma & $90 / 96$ & Texas \\
\hline J6 & Varón & 29 & Jaumave & San Vicente & 02/ 04 & Carolina del N \\
\hline J7 & Varón & 67 & Jaumave & San Antonio & $58 / 88$ & $\begin{array}{l}\text { Florida, Texas, Carolina del } \\
\text { Norte, N. Jersey, Missouri }\end{array}$ \\
\hline J8 & Mujer & 37 & Jaumave & San Lorencito & $91 / 92$ & Florida, Virginia \\
\hline J9 & Varón & 29 & Jaumave & Jaumave & $01 / 02$ & Texas \\
\hline J10 & Mujer & 29 & Jaumave & El nogal & $98 / 08$ & Florida \\
\hline J11 & Mujer & 28 & Jaumave & Matías García & $01 / 02$ & Virginia \\
\hline SC 1 & Varón & 43 & San Carlos & Barranco azul & $79 / 07$ & $\begin{array}{l}\text { Texas, Carolina del Norte, } \\
\text { Virginia, Florida }\end{array}$ \\
\hline SC 2 & Varón & 28 & San Carlos & Barranco azul & 03/ 04 & Texas, Carolina del Norte \\
\hline SC 3 & Varón & 50 & San Carlos & Los Angelitos & $78 / 07$ & Texas, Minnesota \\
\hline SM 1 & Varón & 32 & Soto la Marina & Soto la Marina & $04 / 07$ & Texas, Virginia, Florida \\
\hline SM 2 & Varón & 52 & Soto la Marina & Soto la Marina & $00 / 04$ & Dakota del Sur \\
\hline SM 3 & Mujer & 49 & Soto la Marina & Tampiquito & $77 / 78$ & Texas \\
\hline T 1 & Varón & 30 & Tula & 20 de Noviembre & $04 / 07$ & Texas \\
\hline
\end{tabular}




$\begin{array}{lllllll}\text { T2 } & \text { Varón } & 30 & \text { Tula } & \text { Tanque Blanco } & 97 / 07 & \text { Georgia } \\ \text { T3 } & \text { Varón } & 39 & \text { Tula } & \text { Tanque Blanco } & 85 / 06 & \text { Texas, Carolina del Norte } \\ \text { T4 } & \text { Mujer } & 48 & \text { Tula } & \text { Tanque Blanco } & 98 / 06 & \text { Georgia } \\ \text { T5 } & \text { Varón } & 29 & \text { Tula } & \text { 20 de Noviembre } & 01 & \text { Carolina del Norte } \\ \text { T6 } & \text { Varón } & 57 & \text { Tula } & \text { Terrones Benitez } & 79 / 81 & \text { Texas } \\ \text { T7 } & \text { Mujer } & 28 & \text { Tula } & \text { Celso huerta } & 97 / 00 & \text { Texas y Carolina del N } \\ \text { T8 } & \text { Varón } & 39 & \text { Tula } & \text { Los Charcos } & 05 & \text { Texas } \\ \text { T9 } & \text { Varón } & 39 & \text { Tula } & \text { Tanque Blanco } & 98-07 & \text { Carolina del N; Tennessee } \\ \text { T10 } & \text { Varón } & 45 & \text { Tula } & \text { Tanque Blanco } & 06 / 07 & \text { Texas, Georgia } \\ \text { T11 } & \text { Varón } & 41 & \text { Tula } & \text { Tanque Blanco } & 02 / 07 & \text { Texas, Florida, Michigan } \\ & & & & & & \text { Georgia } \\ \text { T12 } & \text { Mujer } & 27 & \text { Tula } & \text { 20 de Noviembre } & 06 / 07 & \text { Carolina del Norte } \\ \text { T13 } & \text { Varón } & 39 & \text { Tula } & \text { Rancho Nuevo } & 98 / 02 & \text { Texas } \\ \text { VH1 } & \text { Varón } & 41 & \text { Valle Hermoso } & \text { Flores Magón } & 88 / 89 & \text { Florida, Michigan } \\ \text { VH 2 } & \text { Varón } & 56 & \text { Valle Hermoso } & \text { Flores Magón } & 75 / 80 & \text { Louisiana, Tennessee } \\ \text { V1 } & \text { Varón } & 30 & \text { Victoria } & \text { El Olivo } & 01 / 02 & \text { lowa Minnesota } \\ \text { V2 } & \text { Varón } & 49 & \text { Victoria } & \text { La Presa } & 95 / 97 & \text { Tennesee } \\ \text { V3 } & \text { Mujer } & 28 & \text { Victoria } & \text { Rancho Nuevo } & 97 / 01 & \text { Minnesota } \\ \text { V4 } & \text { Varón } & 42 & \text { Victoria } & \text { El Olivo } & 88 / 07 & \text { Atlanta, Texas, Washington, } \\ \text { V5 } & \text { Mujer } & 33 & \text { Victoria } & \text { Otilio Montaño } & 01 / 07 & \text { Missouri, Carolina del Norte } \\ \text { V11 } & \text { Mujer } & 46 & \text { Villagrán } & \text { Guadalupe Victoria } & 86 / 02 & \text { Texas, Florida, Nueva } \\ & & & & & & \text { Jersey, Missouri, } \\ & & & & & \end{array}$

Fuente: Elaboración propia.

El trabajo de campo se extendió hasta llegar a una saturación del campo de diferencias en la producción discursiva de los hablantes (Coyne 1997: 629); de modo que la muestra seleccionada hizo posible elaborar un modelo discursivo que resistió el contraste con el nuevo material cualitativo recopilado sin sufrir alteraciones significativas (Castro Nogueira, M. A. y L. Castro Nogueira 2001: 181).

\section{EMIGRACIÓN Y AISLAMIENTO SOCIAL}

El concepto de "aislamiento social" no ha recibido la suficiente atención en el estudio de la pobreza. Dos conceptos de carácter más holístico, la "marginación" y la "exclusión social", son los que presentan un mayor desarrollo. Estos términos hacen referencia a una sociedad que produce desigualdades crecientes, describen un proceso más que una condición, y expresan situaciones de discriminación cuya naturaleza no es únicamente socioeconómica. El término "exclusión social" implica discriminación de carácter multidimensional (Walker 1997; Schucksmith y Chapman 1998), mientras que el concepto de "marginación" incluye la ausencia de un rol económico articulado con el sistema productivo (De Lomnitz 1983: 17). 
El concepto de "aislamiento social" al igual que los dos anteriores aparece focalizado en los lazos que ligan el individuo a la sociedad; sin embargo, es mucho más restrictivo. La "marginación" y la "exclusión social" incluyen el "aislamiento social". Una persona aislada socialmente sufre de marginación y de exclusión social. Pero no todos los marginados y excluidos sociales padecen el aislamiento social.

El "aislamiento social" carece de connotaciones de carácter económico, y hace una referencia exclusiva al desvanecimiento de las esferas y soportes relacionales del individuo. Wilson (1987: 60) definió este término como "la falta de contacto o interacción con individuos e instituciones que representan a la sociedad" y lo consideró como el concepto teorético clave, explicativo de las dislocaciones sociales, pauperización y deterioro de los centros urbanos. Chávez et al. (2006: 1017) definen la experiencia del aislamiento social como una ausencia de redes sociales o falta del soporte de amigos y familiares. García (2007: 64) añade a estos elementos una ausencia de actividad social o interacción recreacional de carácter formal o informal. Hiott et al. (2008: 36) suman a los rasgos anteriores con la dificultad de expresar los sentimientos personales a otras personas. Otros autores enfatizan el aislamiento geográfico o residencia en espacios apartados (Kim-Godwin et al. 2004: 275; Magaña y Hovey 2003: 82).

El aislamiento social, en cuanto implica una ausencia de soportes relacionales (Raya Díez 2005: 256), una reducción de la interacción social a un único grupo específico de pares 0 a un aislamiento general del entorno social (Espluga et al. 2004: 50), y una degradación progresiva de la participación social (García Martínez y Sánchez Lázaro 2001), tiene connotaciones profundamente negativas. La centralidad de este concepto en el estudio de los trabajadores migratorios empleados en la agricultura se encuentra en el hecho de que el "aislamiento social" ha sido asociado al consumo de alcohol y sustancias estupefacientes (Kim-Godwin et al. 2004: 275; García 2007: 64), y a sentimientos de tristeza, depresión (Parra-Cardona et al. 2006: 363) y ansiedad (Hiott et al. 2008: 36).

A lo largo de más de un siglo de intercambio migratorio entre México y Estados Unidos los jornaleros indocumentados mexicanos han estado expuestos a largas jornadas laborales y estrictas condiciones de trabajo. Además, no se les ha permitido disfrutar de momentos de esparcimiento, ya que se ven obligados a pasar su tiempo de ocio escondidos por miedo a ser deportados (Trigueros y Rodríguez Piña 1988: 212). Por lo tanto, los jornaleros migratorios indocumentados, que se encuentran aislados físicamente de las poblaciones cercanas que rodean las explotaciones agrarias, constituyen posiblemente el grupo social que presenta un nivel más elevado de aislamiento social en Estados Unidos.

Los trabajadores rurales tamaulipecos que cruzaron sin papeles a los Estados Unidos guardan generalmente un recuerdo amargo de la experiencia migratoria. Trabajar en la agricultura estadounidense es definido como "lo más triste que puede haber" (VI 1). El inmigrante empleado en la agricultura contempla su estancia en el país de destino como un sacrificio realizado para sacar adelante a su familia. Por ello da por sentado que en el país de inmigración únicamente pasará penurias. Como señalaba uno 
de los entrevistados "toda la gente que se va para allá, se va a sufrir" (SC 1). Aun así, la extrema dureza del trabajo y la situación de aislamiento social es difícil de soportar para muchos jornaleros migratorios (Izcara Palacios 2006: 111).

\section{EL ENCERRAMIENTO EN LOS CAMPOS DE LABOR}

El encerramiento en los campos de labor es el elemento que mejor ilustra la situación de aislamiento social que sufren los jornaleros tamaulipecos que cruzaron de modo subrepticio a los Estados Unidos. Los inmigrantes indocumentados empleados en la agricultura viven escondidos, con un miedo permanente a ser descubiertos por las autoridades migratorias (Izcara Palacios 2009c: 102). Los empleadores son reacios a permitir que los jornaleros que no tienen documentos salgan de los ranchos; así minimizan el riesgo de perder trabajadores, que serían aprehendidos si son detectados por las autoridades migratorias. Expresiones como: "el patrón no quería que fuéramos al pueblo" (J 3); "el patrón siempre nos recomendó que no anduviéramos mucho en el pueblo [...] que nos regresáramos para que no tuviéramos problemas" (SM 2); "(el patrón) no quería que saliéramos" (J 9) se repiten en muchas entrevistas. Para evitar que los trabajadores indocumentados salgan durante los días de descanso, son los capataces quienes generalmente se encargan de ir a las poblaciones cercanas para adquirir aquellos productos que necesiten.

Los indocumentados conviven siempre con el miedo a ser descubiertos por las autoridades migratorias. En el único lugar donde se encuentran seguros es en los lugares de trabajo, ya que el Servicio de Inmigración raramente les busca allí. Por el contrario, cuando salen de los ranchos se encuentran mucho más expuestos. Por lo tanto, como se muestra en las siguientes citas, pasan meses e incluso años recluidos en los campos de labor, ya que desplazarse a la ciudad en busca de esparcimiento es un riesgo que la mayoría no están dispuestos a correr.

"No podíamos salir a ningún lado, pues nos agarraba la migra, pues allá en Oklahoma está bien duro para los que no tienen papeles, andan sobre nosotros." (A 3).

"No conocía otra cosa más que el rancho, pues teníamos miedo a que nos agarraran y nos echaran para acá." (AM 1).

"No podías salir a ningún lado; de echo no podíamos salir ni siquiera al pueblo más cercano porque tienes el temor de que te agarre la migra y te reporten otra vez para atrás." (T 8).

"Porque pues de ilegales, pues andas casi escondido, porque pues con miedo de que te vaya a encontrar la migra y ya te deporten" (J 11). 
Los datos de la tabla 1 muestran de modo más gráfico la opinión de los trabajadores migratorios indocumentados de Tamaulipas sobre los campos agrícolas en Estados Unidos. Un $62 \%$ de los jornaleros tamaulipecos manifestaban en las entrevistas que dentro de los campos de labor gozaban de una situación de seguridad, ya que éstos no eran escrutados por las autoridades migratorias. Asimismo, un $36 \%$ de los entrevistados consideraba que únicamente eran perseguidos por las autoridades migratorias cuando salían de los campos agrícolas y se encontraban ociosos en poblaciones cercanas a las explotaciones agropecuarias donde trabajaban.

Tabla 1.

Opinión de los trabajadores migratorios indocumentados tamaulipecos sobre los campos de labor en Estados Unidos

\begin{tabular}{|l|c|c|c|c|c|c|c|c|}
\hline Edad de los entrevistados & \multicolumn{2}{|c|}{$<30$} & \multicolumn{2}{c|}{$30-45$} & \multicolumn{2}{c|}{$>45$} & \multicolumn{2}{c|}{ Total } \\
\hline \multirow{2}{*}{$\begin{array}{l}\text { Número total y porcentaje de } \\
\text { entrevistados }\end{array}$} & Núm. & $\%$ & Núm. & $\%$ & Núm. & $\%$ & Núm. & $\%$ \\
\cline { 2 - 10 } & 16 & 32 & 18 & 36 & 16 & 32 & 50 & 100 \\
\hline $\begin{array}{l}\text { Manifestó que los campos de labor } \\
\text { no son escrutados por las } \\
\text { autoridades migratorias. }\end{array}$ & 9 & 56 & 12 & 67 & 10 & 62 & 31 & 62 \\
\hline $\begin{array}{l}\text { Señaló que los jornaleros indocu- } \\
\text { mentados únicamente son per- } \\
\text { seguidos por el INS* cuando se } \\
\text { encuentran ociosos fuera de las } \\
\text { explotaciones agropecuarias. }\end{array}$ & 6 & 37 & 9 & 50 & 4 & 25 & 19 & 36 \\
\hline
\end{tabular}

Fuente: Elaboración propia a partir de una muestra intencional de 50 jornaleros indocumentados. Los resultados no son respuestas a un cuestionario; sino opiniones y puntos de vista expresados en una interacción conversacional conducida con una guía temática abierta.

*INS Servicio de Inmigración y Naturalización.

El entorno de encerramiento y el temor a la deportación conducen a una situación de inestabilidad emocional, que se refleja en la siguiente cita: "Fue muy difícil porque vivía con el miedo de que me fueran a agarrar; siempre escondido y cuidándome que no vinieran, porque no quería que me deportaran, pues dicen que cuando te agarran te mandan lejos del lugar de donde vives. Eso me deprimía mucho; siempre viví con los nervios porque no contaba con papeles" (A 2). 
La falta de libertad de movimientos constituye uno de los aspectos más amargos de la emigración. Los entrevistados aluden a una reclusión en los sitios de trabajo. La lectura de las entrevistas deja la impresión de que las autoridades migratorias siempre les vigilan de cerca. Lo que resulta paradójico es que los informantes señalan que son muy raras las redadas que se realizan en los campos de labor. Las explotaciones agrarias son definidas como una especie de fortalezas donde encuentran seguridad (Izcara Palacios 2009b: 35). Como contraste, cuando salen perciben el acecho permanente de la "migra". De este modo, los campos de trabajo se tornan en una especie de prisión de la cual no pueden escapar.

"Como no tenía papeles no podía salir a pasear; casi escondida porque por ahí pasa muy seguido la migración." (J 2)

"Hasta parece que está uno encerrado porque por la migra no puede uno andar como la gente de allá. Uno no es libre." (EM 2).

"uno está ahí cautivo, teníamos que estar ahí sin salir." (V 3).

"cuando era ilegal pues no me podía andar paseando campantemente porque luego me agarraba la migra" (A 1).

"jamás salía del rancho y cuando había registro de migración nos avisaban y nos escondían." (J 2).

"No salíamos, y otra peor, ahí estábamos encerrados." (G 2).

"tampoco puedes andar muy tranquila, paseándote por el pueblo, porque como uno anda así pues de ilegal, pues casi anda escondida" ( $(\mathrm{B})$.

Los indocumentados envidian la libertad de movimientos que tienen aquellos jornaleros que pueden acreditar su estancia legal en Estados Unidos. Como señalaba un entrevistado: "Ellos andan con toda libertad, pues andan en su país. Es difícil para uno que anda de ilegal, casi escondido, tiene que aguantarse" (T 7). Por lo tanto, cuando regresan a sus comunidades uno de los aspectos que más valoran es la recuperación de la libertad. Frente a la situación de encerramiento que sufren en Estados Unidos, un país en el que están obligados a observar una conducta sumisa y a "portarse bien", en Tamaulipas se sienten "a gusto". Un jornalero señalaba: "se siente uno como que tiene que portarse bien; pues, porque uno anda en otro país [...] sí le echa menos uno a hacer lo que se le pegue la gana" (T 6). Son numerosas las entrevistas en las que se contrasta el ostracismo sufrido en el agro estadounidense con la rica interacción recreacional de que disfrutan en Tamaulipas. Un jornalero indicaba: "No más te quedas encerrado como los animales, y aquí uno es libre, puede salir a andar en las calles" (V 4). Otro informante manifestaba: "sí ganas bien, pero no te diviertes como aquí" (J 9). Por ello la experiencia de trabajar en Estados Unidos conduce a una mayor valoración de las libertades de las que gozan en México. 
Aquellos que sufren una mayor pérdida de libertad son los trabajadores a quienes el patrón les facilitó la entrada ilegal en el país. Muchos empresarios agrarios estadounidenses, con objeto de disponer de mano de obra sumisa y disciplinada, la reclutan directamente en Tamaulipas. Cuando el patrón financia el tráfico de indocumentados se reduce el riesgo económico de la emigración, ya que en caso de ser aprehendido por las autoridades migratorias el inmigrante no pierde su inversión; además de que no precisa de un capital inicial para cruzar la frontera (Izcara Palacios 2010a: 67). Sin embargo, esto implica una mayor atadura a los empleadores, que les ofrecen salarios muy mermados. Los trabajadores, especialmente las mujeres, se sienten agradecidos y comprometidos a trabajar para aquel empleador que facilitó su entrada en el país vecino, de modo que pueden padecer durante años una situación de servidumbre. Una jornalera exponía: "nos sentíamos así como de que pues no teníamos libertad de que si nos queríamos ir a otro lugar, porque pues se siente uno comprometido, porque pues lo ayudó para estar allá. Así como que pues, que le debías" (V 3).

\section{LA CARENCIA DE SOPORTES RELACIONALES}

La carencia de soportes relacionales es otra de las características del entorno social que rodea al jornalero migratorio. En el lugar de trabajo perdura un abrumador sentimiento de soledad, hasta el punto de que en numerosas ocasiones el inmigrante no encuentra a nadie con quien dialogar abiertamente (Magaña y Hovey, 2003: 82). En este sentido, muchos de los entrevistados afirmaban haber hecho muy pocas amistades en Estados Unidos. Como subrayaba uno de los jornaleros: "uno allá sólo se pone triste en los momentos en los que está solo y no le dan ganas de andar haciendo amistades" (V 1). Los trabajadores agrarios, debido a su movilidad, son quienes más carecen del apoyo de redes sociales y lazos familiares (Chávez et al. 2006: 1017). La separación de los amigos y la familia, la soledad, las duras condiciones de trabajo y la falta de tiempo de ocio han sido documentados como los principales factores de estrés padecidos por los jornaleros migratorios (Magaña y Hovey 2003: 79 y 82; Kim-Godwin 2004: 274 y 275; Parra Cardona et al. 2006: 371). Como resultado, los entrevistados expresaban una lucha interior entre el deseo de dejar el trabajo y regresar a Tamaulipas, y el deber de aguantar el encerramiento y las duras jornadas laborales para mantener a su familia. Como se aprecia en la siguiente cita, cuando echan de menos el calor familiar, o sufren el cansancio de las agotadoras jornadas laborales, inmediatamente pasa por sus mentes la idea de desistir y abandonar los ranchos donde trabajan: "ahí te empiezas a acordar de tu familia y tú solo, con ganas de salir corriendo, y ya nunca regresar" (EM 1). Aunque, inmediatamente vuelve a sus mentes el propósito de su sacrificio. Como señalaba uno de los entrevistados: "nos daba por querernos venir para acá, y pues ese no era el caso, uno se tenía que sacrificar por los que quiere" (V 1). La soledad y angustia de trabajar en un entorno tan precario es soportada porque el mercado laboral tamaulipeco no les ofrece empleos estables (Andrade Rubio 2008: 107). 
Los jornaleros indocumentados de Tamaulipas mantienen un contacto telefónico con los familiares. La principal ocasión para hablar con estos es cuando les envían las remesas (generalmente una vez al mes). Sin embargo, el contacto telefónico con los familiares en ocasiones llega a elevar su nivel de estrés; sobre todo, si estuvieron subempleados 0 desempleados ${ }^{3}$. Muchas economías familiares dependen casi enteramente de las remesas, ya que en ocasiones el marido se deshizo de sus pertenencias para poder emigrar y dejó a su esposa e hijos sin ningún medio de supervivencia (Izcara Palacios 2010b). Como consecuencia, el emigrante aparece casi obligado a comunicar a su familia que su situación en los Estados Unidos es buena. Cuando éste no tiene ningún ahorro (porque no pudo trabajar durante un periodo determinado) comunicarse con los familiares se torna traumático ya que sabe que necesitan dinero; pero no puede enviarles nada; tampoco puede hablarles abiertamente sobre su situación, porque se preocuparían. Además, cuando se comunica con familiares o con sus paisanos debe mantener una actitud de triunfador. El emigrante no puede regresar a Tamaulipas hasta haber acumulado un ahorro que le permita ascender socialmente en su comunidad (Izcara Palacios 2009a: 28) ya que si regresa con las manos vacías será visto como un fracasado. De este modo, tener que aparentar que todo está bien cuando se comunican con sus familiares en ocasiones puede llegar a ser más estresante que el ambiente de soledad y el entorno laboral tan precario que padecen.

\section{LA AUSENCIA DE INTERACCIÓN RECREACIONAL}

La falta de acceso a espacios y tiempos para el ocio y el esparcimiento es un elemento que acentúa la situación de aislamiento social de los jornaleros migratorios indocumentados de Tamaulipas. El tiempo que éstos permanecen en Estados Unidos cada vez que cruzan la frontera, que puede extenderse desde unos pocos meses hasta una década, carecen de un acceso a espacios y actividades de ocio donde poder liberar el estrés acumulado tras agotadoras jornadas de trabajo. Expresiones como: "no hay mucho donde divertirse sin salir a la ciudad y arriesgarte a que te agarre la migración" (J 1); "allá no andas que en fiestas ni nada. Allá uno se la pasa trabajando" ( $\mathrm{J} 3$ ), o "así era todos los días, no había diversión, sólo trabajar" ( $\mathrm{J} 10$ ), se repiten frecuentemente en las entrevistas. Las jornadas laborales pueden extenderse hasta catorce horas, y en ocasiones los jornaleros trabajan durante toda la semana, también los domingos. La elevada capacidad de trabajo, por la cual los braceros mexicanos han sido elogiados y apreciados en los Estados Unidos durante más de un siglo (Thompson 1956: 77; Alarcón 2007: 161), únicamente se explica por la situación de confinamiento que padecen.

\footnotetext{
${ }^{3}$ La tasa de desempleo de los asalariados agrarios en Estados Unidos es muy elevada. Únicamente durante el periodo estival el desempleo desciende por debajo del 20 \% (Izcara Palacios, 2009d: 129).
} 
La vida de los jornaleros indocumentados se reduce básicamente al trabajo; comienzan a trabajar con el alba, permanecen en el campo hasta el anochecer, y cuando regresan del trabajo están tan agotados que sólo quieren descansar. La única actividad de esparcimiento para muchos jornaleros consiste en ingerir alcohol durante los fines de semana. Embriagarse durante los días de asueto constituye para muchos jornaleros la única oportunidad de liberarse del estrés generado por el trabajo. El consumo de narcóticos también está suficientemente documentado (García 2007). Sin embargo, con frecuencia esto conduce a enfrentamientos entre los trabajadores, que acentúa aún más el problema del aislamiento social. Como señalaba uno de los entrevistados: "primero fue bien, y pues ya después, o sea como a unos les gusta tomar, se toman unas cervezas y ya punto borrachos, pues, o sea le dicen cosas a uno, y ya empiezan ahí los problemas, se quieren pelear con uno y pues, sí pelean con uno y pues uno no más se defiende, verdad" (T 2).

\section{LA COMPETENCIA POR EL EMPLEO}

En la agricultura, una actividad caracterizada por grandes variaciones estacionales en el volumen de mano de obra demandada, la disposición de una reserva de trabajadores es una condición necesaria para poder desarrollar las tareas a tiempo, y evitar pérdidas económicas cuantiosas. El sector agrario estadounidense ha encontrado este filón en los trabajadores indocumentados mexicanos. Pero, la consecuencia de este exceso de mano de obra es una competencia por el empleo que crea fisuras en el colectivo jornalero y acentúa los procesos de aislamiento social.

En primer lugar, llegar nuevo a un lugar de trabajo acrecienta el rechazo de aquellos trabajadores que llegaron antes. La llegada de nuevos trabajadores incrementa la competencia por el empleo y conduce a una reducción salarial, ya que durante una misma temporada los jornales fluctúan en función del apremio del trabajo, de la dificultad de la labor y de la disponibilidad de trabajadores. La actitud de rechazo de los trabajadores más veteranos hacia los nuevos se manifiesta no únicamente en miradas y gestos despectivos, o en expresiones verbales intimidatorias; sino también en agresiones físicas. Como señalaba uno de los entrevistados: "en donde uno vaya a trabajar, pues llega de nuevo a un trabajo y hay gente que tiene cinco o seis meses trabajando ahí, y llega uno de nuevo a pedir trabajo [...] y pues, te miran con mala cara, te hacen gestos y pues a mi me daba pena, me daba vergüenza. Me levantaba al último para poder desayunar [...] Sí vi que otros se golpearon y era claro por lo mismo. Como ellos tenían más tiempo, se creían más" ( $\mathrm{J} 1$ ).

En segundo lugar, debido a que en la agricultura generalmente se trabaja a destajo las diferencias salariales originadas por la diferente capacidad de trabajo de cada jornalero conducen con frecuencia a enfrentamientos y rivalidades entre los mismos compañeros de trabajo. Las siguientes expresiones reflejan las envidias originadas por las diferencias en los salarios percibidos: 
"los más flojos les daba envidia porque a la hora de la paga, [... ] como a ellos les pagaban menos pues se enojaban" ( $\mathrm{V} 1)$.

"es como todo, en cualquier chamba todos te van a querer quitar, que porque tú ganas mejor o menos; siempre hubo esa envidia" (EM 1).

En tercer lugar, aquellos que tienen documentos perciben a los indocumentados como una amenaza a sus expectativas laborales y oportunidades económicas, ya que los últimos tienden a aceptar salarios inferiores. Esto genera enfrentamientos entre estos dos colectivos. Los indocumentados ven con desesperación que ellos reciban salarios más bajos que los jornaleros que tienen los papeles en regla, aún cuando los primeros tienden a trabajar más horas. Esto genera un conflicto y escisión entre los trabajadores legales y los ilegales. Uno de los entrevistados se expresaba del siguiente modo: "nosotros como ilegales sentíamos que trabajábamos más; pues los legales tenían derechos por tener contratos; pero, nosotros nada, y eso hacía que algunos compañeros se enojaran [...] y eran peleas bien feas, hasta descalabrarnos" (A 3). Como contraste, los documentados no ven bien que los patrones empleen trabajadores ilegales, que abrumados por las penurias se esfuerzan más en el trabajo, trabajan más horas, y se conforman con peores salarios. Para ellos el empleo de mano de obra indocumentada no atenta únicamente contra las leyes estadounidenses; sino que les impide llevar una vida digna. Los jornaleros que residen legalmente en Estados Unidos tienen que afrontar un elevado costo de vida. Por el contrario, los indocumentados, que no contemplan un proyecto de vida a largo plazo en el país de acogida, están más dispuestos a malvivir mientras permanecen en el extranjero para acumular recursos que les permitan mejorar su posición económica en su lugar de origen (Blejer et al. 1982: 182; Izcara Palacios 2009a: 28). El grupo social de referencia de estos últimos es su comunidad de origen; como consecuencia, se conforman con salarios inferiores ya que el coste de vida en su lugar de procedencia es comparativamente muy bajo. Esto genera una competencia desleal que conduce a un deterioro de las oportunidades económicas de los trabajadores que tienen su residencia en los Estados Unidos. El resultado es una situación de tensión entre la mano de obra legal y los inmigrantes indocumentados. Son muchas las entrevistas en las que se relata una situación de rechazo de los primeros hacia los últimos.

"una vez, pues fuimos a pizcar; eso me pasó a mi y pues nos decían pinches mojados y ahí pues hasta nos echaron la camioneta". (G 1).

"había discriminación, porque uno andaba ahí. Creían que uno les iba a quitar el trabajo a ellos [...] sí había discriminación, como le digo, con la misma gente de uno, con la misma raza de uno [...] porque ellos traían papeles y nosotros no". (VI 1).

"se molestan porque los ilegales desempeñamos mejor los trabajos y siempre los patrones nos mantienen ocupados y eso a ellos les molesta, y a los residentes los 
desocupan más fácilmente y creo que esa es una envidia que nos tienen a nosotros los mexicanos ilegales". (B 1).

"yo creo que sienten que si uno va a trabajar allá pues les anda quitando el trabajo; entonces pues sí, se ponían así medios canijos". (T 9).

También aparece una falta de contacto interpersonal y una relación conflictiva entre los trabajadores de origen hispano y la población afro-americana empleada en las explotaciones hortofrutícolas. Uno de los entrevistados decía: "yo alguna vez me peleé con un negro, porque esos son muy conflictivos y todo quieren ser y se creen los amos del país, son bien fastidiosos" (EM 1). Otro se expresaba del siguiente modo: "había unos negros que sí nos miraron mal [...] Ya nos habían dicho unos compañeros, que los negros no nos quieren mucho a los mexicanos". (V 2). Los trabajadores mexicanos han ido encajando en los nichos laborales de menor prestigio, caracterizados por unas condiciones sociolaborales más desfavorables, y poco a poco están acaparando los empleos que antes realizaban los grupos sociales más marginales, especialmente la población afroamericana (Hahamovitch 2002: 104; Quandt et al. 2004: 119). Las tareas agrícolas que en lugares como el sureste de Estados Unidos décadas atrás eran realizadas por la población de color, ahora han pasado a las manos de los inmigrantes mexicanos.

Finalmente, los jornaleros tamaulipecos también describen una relación tensa con otros inmigrantes centroamericanos empleados en el sector agrario estadounidense. Uno de los entrevistados decía que el mal trato recibido por éstos al cruzar México generaba un resentimiento hacia los mexicanos: "esa gente, de Honduras, de por allá, que pues ellos cuando pasan por aquí (México) también pues los tratan mal, y pues por eso también a uno no lo quieren muy bien." (T 2).

Como resultado de las escisiones generadas por la competencia por el empleo algunos estudios han constatado que los trabajadores agrarios presentan unos niveles más bajos de confianza en los demás que otros grupos sociales (Chávez et al. 2006: 1023). Este clima de desconfianza aparece vívidamente plasmado en el siguiente relato: "todos nos conocíamos y pues lo que hacíamos era cuidarnos todos de todos, o sea desconfiar. No sabíamos bien quien éramos, no sabíamos si alguno estaba huyendo acá en México porque hizo algo malo; así que había que cuidarnos, pero todos tratábamos de llevárnosla por el lado amable con los otros". (AM 2).

Esta última cita implica que la construcción legal de la ilegalidad no únicamente relega a los indocumentados a un mercado laboral sumergido (Calavita 1998: 529) y provoca una estigmatización de los mismos que favorece su explotación (Heyman 1998 y 2001); sino que además conduce a una interiorización de la condición de ilegal/criminal. La criminalización que la ley migratoria hace de la inmigración subrepticia hace que los indocumentados lleguen a considerarse delincuentes. Como consecuencia, el aislamiento social del inmigrante muchas veces se enraíza en una desconfianza hacia el otro, derivada de una infundada e injustificable suposición de que éste realmente pueda haber cometido un crimen. Esta suposición es más subrayada hacia aquellas personas 
que proceden de otros países: "no hablábamos con los de afuera, por lo mismo que no les hacíamos mucha confianza y no conoces a la gente, como son de otro país, no sabes si mataron a alguien" (J 9).

\section{LA SOLIDIFICACIÓN DE LOS LAZOS DE AMISTAD CON EL GRUPO DE PARES}

El aislamiento social no ha sido entendido únicamente como un apartamiento social general de la persona afectada; sino también como una reducción de los contactos interpersonales a un único grupo específico de pares o iguales (Espluga et al. 2004: 51) al mismo tiempo que se produce un retraimiento de las corrientes predominantes (mainstream) de la sociedad (Kaztman 2001: 183).

La naturaleza de las relaciones sociales entre pares no se reduce únicamente a expresiones de falta de confianza y ruptura de lazos; sino que también es posible constatar la experiencia contraria: la fragua de sólidas redes de amistad. En aquellos ambientes laborales donde los trabajadores presentan una mayor homogeneidad (todos son ilegales, provienen de la misma región o país, su experiencia migratoria es reducida y las diferencias salariales son poco visibles) y el conocimiento de sus biografías es más pormenorizado, la confianza dentro del grupo de pares es mayor y los lazos de unión se tornan más férreos. En este sentido, cinco entrevistados explicitaron la idea de una fuerte solidificación de los lazos de amistad entre el grupo de pares. El común denominador de todos estos informantes consistía en haber trabajado en explotaciones donde predominaban los jornaleros indocumentados y donde las diferencias salariales no eran perceptibles. Paradójicamente los jornaleros que expresaban la idea de una solidificación de los lazos de amistad con el grupo de pares hablaban muchas veces de su experiencia laboral en Texas, un estado donde los salarios agrarios son muy bajos y las condiciones sociolaborales son poco atractivas. Sin embargo, lo que distingue la agricultura tejana (sobre todo a las explotaciones agrarias de la franja fronteriza) del resto del país es el empleo casi exclusivo de trabajadores indocumentados, la ausencia de mano de obra local, y la homogeneidad de los salarios percibidos. Además, muchos de los jornaleros empleados en esta zona son tamaulipecos.

"cuando uno está fuera se mira uno como hermano, con una gran amistad". (SC 1).

"con todos me llevaba muy bien [...] si a alguno le faltaba dinero pues nos cooperábamos y lo ayudábamos entre todos". (T 1).

"Había mucha ayuda unos con otros, todos estábamos en la misma condición y siempre éramos muy abiertos, hablábamos de nuestras familias en México y de las ganas que teníamos de volver acá". (AM 1).

"andas en un lugar que no conoces y pues todos estamos allá reunidos por lo mismo, por el dinero, para enviarles a nuestras familia [...] entonces no más el compañerismo es el que se da en ese tipo de situaciones." (T 8). 
"a veces te llevabas mejor con personas desconocidas que con personas que ya conoces, por lo mismo de que te conocen, saben como tratarte; en cambio, cuando es una persona que ni conoces bien, entonces te cuenta sus cosas, te pide algo si necesita 0 te presta, o sea nace una amistad". (T 10).

Por el contrario, cuando el grupo de jornaleros es más diverso (unos tienen documentos y otros son indocumentados, hay trabajadores autóctonos y foráneos, y unos jornaleros llegaron recientemente mientras otros tienen una amplia experiencia laboral en ese empleo) y el conocimiento de las biografías personales es más difuso e impreciso, los niveles de confianza entre los trabajadores son más bajos, y los altercados y disputas entre ellos son más frecuentes.

Si se entiende el "aislamiento social" como el último estadio de la exclusión social, que es cuando el individuo pierde todos sus vínculos sociales (familiares y de amistad) y colectivos (sindicales, etc.), y padece una situación de soledad (Vite Pérez 2006: 11), habría que concluir que únicamente en el último escenario se produce una situación de aislamiento social. Sin embargo, el "aislamiento social" también incluye otros elementos como: retraimiento general del entorno social y ausencia de participación social e interacción recreacional. Por lo tanto, la construcción de redes de amistad con los compañeros de trabajo en los campos agrícolas estadounidenses no elimina el aislamiento social, ya que todos los jornaleros indocumentados padecen una situación de encerramiento, aislamiento geográfico y separación prolongada de la familia. En este sentido, podría concluirse que la naturaleza de las relaciones sociales entre pares (de amistad o enfrentamiento) incrementa o disminuye el grado de aislamiento social de los trabajadores ilegales; pero no lo elimina (Izcara Palacios 2009c: 103). Es decir, en ambos casos se da una situación de aislamiento social. En el primer caso porque la interacción social aparece reducida a un único grupo específico de pares. En el último porque se produce un aislamiento total del trabajador. En los dos escenarios el individuo padece una situación de reclusión, persecución, falta de interacción recreacional, y retraimiento del mainstream de la sociedad.

\section{Conclusiones}

El aislamiento social es uno de los aspectos más dramáticos de la inmigración irregular. En el caso norteamericano éste es el producto de una política migratoria focalizada en el lado de la oferta y despreocupada por la demanda de mano de obra migratoria (Izcara Palacios 2010). Por una parte se criminaliza al inmigrante; pero, por otra, se le abren las puertas a empleos precarios creando una forma moderna de esclavitud.

Los jornaleros migratorios tamaulipecos están expuestos a un sinnúmero de penurias para cruzar la frontera de forma subrepticia. El mayor costo del trayecto se ha traducido en estancias más prolongadas, que pueden sobrepasar los cinco años. Dentro de Estados Unidos encontrar empleo no es el principal problema. Su conocimiento y habi- 
lidad para realizar las tareas más exigentes (sobre todo la pizca de frutas) les convierte en una mano de obra apreciada y demandada por los empresarios agrarios. Además, los campos de labor constituyen una zona de seguridad. Es de sobra conocido que más de la mitad de los jornaleros empleados en el agro estadounidense lo hacen bajo una identidad falsa. Sin embargo, las autoridades migratorias hacen la vista gorda mientras éstos permanezcan encerrados en los campos. Por el contrario, cualquier forma de interacción recreacional fuera de los mismos es perseguida. Como consecuencia, no es raro encontrar a jornaleros mexicanos indocumentados que llegan a permanecer encerrados en el lugar de trabajo durante años, periodo durante el cual su contacto con la sociedad local es prácticamente nulo ${ }^{4}$.

La separación prolongada de amigos y familiares, la carencia de actividad social e interacción recreacional, la dificultad de encontrar una persona en quien confiar o con quien dialogar, y el mismo aislamiento geográfico del lugar de trabajo, se traducen en sentimientos de angustia, depresión, ansiedad y en un abuso del consumo de bebidas alcohólicas. Hiott et al. (2008: 38) concluyen que el facilitamiento de la interacción recreacional de los jornaleros dentro de las comunidades locales ayudaría a disminuir el estrés y a reducir los síntomas de depresión y ansiedad que estos padecen. Sin embargo, los inmigrantes indocumentados temen salir y exponerse a ser deportados. Además, sus empleadores son reacios a que éstos participen en actividades sociales. Por lo tanto, únicamente a través de la regularización de la situación laboral de más de un millón de jornaleros indocumentados que emplea el sector agrario estadounidense podría reducirse el nivel de aislamiento social que padece este colectivo.

\section{RefERENCIAS BibLIOGRÁfICAS}

Alarcón, R. 2007. "Restricciones a la inmigración en Estados Unidos y movimiento agrario en Cabinda, Michoacán (1920-1942)." Relaciones 110: 155-187.

Andrade Rubio, K.L. 2008. "Intermediación laboral, migración y exclusión social: Ios pizcadores de naranja en Tamaulipas." Caleidoscopio: Revista Semestral de Ciencias Sociales y Humanidades 12: 101-114.

Calavita, K. 1998. "Immigration, Law, and Marginalization in a Global Economy: Notes from Spain." Law \& Society Review 32: 529-565.

Carrol, D., R. M. Samardick, U. S. Bernard, S. M. Gabbard y T. Hernández. 2005. "Findings from the

\footnotetext{
${ }^{4}$ En una visita que realicé en el verano del año 2006 a una explotación de cítricos del sur de Florida tuve la oportunidad de entrevistar a un jornalero mexicano indocumentado que llevaba trabajando allí 5 años, y durante este periodo no había salido a ninguna parte. Ya había ahorrado suficiente dinero y deseaba regresar a Oaxaca; sin embargo, había pospuesto su regreso porque gozaba del afecto de su empleador y tenía la esperanza de poder regularizar su situación laboral en un futuro próximo.
} 
National Agricultural Workers S (NAWS) 1997-1998. A Demographic and Employment Profile of United States Farm Workers. US Department of Labor.

Castro Nogueira, M. A. y L. Castro Nogueira. 2001. "Cuestiones de metodología cualitativa." EMPIRIA: Revista de Metodología de las Ciencias Socilaes 4: 165-190.

Chávez, M. L.; B. Wampler y R. E. Burkhart. 2006. "Left Out: Trust and Social Capital Among Migrant Seasonal Farmworkers." Social Science Quarterly 87: 1012-1029.

Coyne, I. T. 1997. "Sampling in qualitative research. Purposeful and theoretical sampling, merging or clear boundaries?." Journal of Advanced Nursing 26: 623-630.

Espluga, J., J. Baltiérrez y L. Lemkow. 2004. "Relaciones entre la salud, el desempleo de larga duración y la exclusión social de los jóvenes en España." Revista Cuadernos de Trabajo Social 17: 45- 62

Fonseca, O. y L. Moreno. 1988. "Consideraciones histórico-sociales de la migración de trabajadores michoacanos a los Estados Unidos de América: El caso de Jaripo". Pp. 19-40 en Migración en el Occidente de México, editado por López Castro, G. y S. Pardo Galván. México: El Colegio de Michoacán.

García, V. 2007. "Meeting a Binational Research Challenge: Substance Abuse Among Transnational Mexican Farmworkers in the United States." The Journal of Rural Health 23: 61 - 67.

García Martínez, J. A. y A. M. Sánchez Lázaro. 2001. "Para profundizar en la temática de la exclusión." Revista Anales de Pedagogía 19: 171-184.

Gilbert, L. 2005. "Fields of hope, fields of despair: Legisprudential and historic perspectives on the AGJOBS Bill of 2003." Harvard Journal on Legislation 42 (2): 417-482.

Hahamovitch, C. 2002. "Standing Idly By: 'Organized' Farmworkers in South Florida during the Depression and World War II". Pp. 89-110 en The Human Cost of Food: Farmworkers' Lives, Labor and Advocacy, edited by Thompson, C. D. and M. F. Wiggins. Austin: University of Texas Press.

Heyman, J. M. 1998. "State Effects on Labor Exploitation." Critique of Anthropology 18: 157-180.

Heyman, J. M. 2001. "Class and Classification at U.S.-Mexico Border." Human Organization 60: 128140.

Hiott, A. E., J. G. Grzywacz, S. W. Davis, S. A. Quandt y T. A. Arcury. 2008. "Migrant Farmworkers Stress: Mental Health Implications." The Journal of Rural Health 24: 32-39.

Izcara Palacios, S. P. 2006. Infraclases rurales. Los trabajadores eventuales agrarios de Tamaulipas (México) y Andalucía (España). México: Plaza y Valdés.

Izcara Palacios, S. P. 2009a. "Privación relativa y emigración: el caso tamaulipeco." Migraciones Internacionales 4: 5-31.

Izcara Palacios, S. P. 2009b. "Militarización de la frontera e inmigración ilegal: Los jornaleros tamaulipecos." Estudios Fronterizos 10: 9-45. 
Izcara Palacios, S. P. 2009c. "La situación sociolaboral de los migrantes internacionales en la agricultura: irregularidad laboral y aislamiento social." Estudios Sociales 17: 83-109.

Izcara Palacios, S. P. 2009d. Trabajadores rurales indocumentados de Tamaulipas en la agricultura de Estados Unidos. México: Plaza y Valdés.

Izcara Palacios, S. P. 2010a. "La adicción a la mano de obra ilegal: Jornaleros tamaulipecos en Estados Unidos." Latin American Research Review 45: 55-75.

Izcara Palacios, S. P. 2010b. "Los factores no salariales en la migración internacional: El ejemplo tamaulipeco." Revista de Ciencias Sociales 16 (3). En prensa.

Izcara Palacios, S. P. y K. L. Andrade Rubio. 2007. "Subempleo e irregularidad laboral: los jornaleros tamaulipecos." Sociología del Trabajo 59: 61-78.

Kaztman, R. 2001. "Seducidos y abandonados: el aislamiento social de los pobres urbanos." Revista de la CEPAL 75: 171-189.

Kim-Godwin, Y. S. y G. Bechtel. 2004. "Stress Among Migrant and Seasonal Farmworkers in Rural Southeast North Carolina." The Journal of Rural health 20: 271-278.

De Lomnitz, L. A. 1983. ¿Cómo sobreviven los marginados? México: Siglo XXI.

Magaña, C. G. y J. D. Hovey. 2003. "Psychosocial Stressors Associated with Mexican Migrant Farm Workers in the Midwest United States." Journal of Immigrant Health 5: 75-86.

Mehta, K., S. M. Gabbard, V. Barrat, M. Lewis, D. Carrol y R. Mines. 2000. "Findings from the National Agricultural Workers S (NAWS) 1997-1998". A Demographic and Employment Profile of United States Farmworkers. Research Report N. ${ }^{\circ} 8$. US Department of Labor.

Mines, R., S. Gabbard y A. Steirman. 1997. The National Agricultural Workers Survey. A profile of U.S. Farm Workers. Demographics, Household Composition, Income and Use of Services. USDL.

Parra-Cardona, J. R., L. A. Bulock, D. R. Imig, F. A. Villarruel y S. J. Gold. 2006. "Trabajando duro todos los días: Learning from the Life Experiences of Mexican-Origin Migrant Families". Family Relations 55: 361-375.

Quandt, S. A.; T. A. Arcury, J. Early, J. Tapia y J. D. Davis. 2004. "Household food security among migrant and seasonal Latino farmworkers in North Carolina." Public Health Reports 119: 68-576.

Rao, P., S. A. Quandt y T. A. Arcury. 2002. "Hispanic Farmworker Interpretations of Green Tobacco Sickness." The Journal of Rural Health 18: 503-511.

Raya Díez, E., 2005. "Categorías sociales y personas en situación de exclusión. Una aproximación desde el País Vasco." Revista Cuadernos de Relaciones Laborales 23 (2): 247- 267.

Shucksmith, M. y P. Chapman. 1998. "Rural Development and Social Exclusion." Sociologia Ruralis 38: 225-242. 
Spener, D. 2001. "El contrabando de migrantes en la frontera de Texas con el nordeste de México: Mecanismo para la integración del mercado laboral de América del norte." Espiral, Estudios sobre Estado y Sociedad 21: 201-247.

Thompson, C. D. 2002. "Layers of loss: Migrants, Small Farmers, and Agribusiness". Pp. 55-86 en The Human Cost of Food: Farmworkers' Lives, Labor and Advocacy, edited by Thompson, C. D. y M. F. Wiggins. Austin: University of Texas Press.

Trigueros, P. y J. Rodríguez Piña. 1988. "Migración y vida familiar en Michoacán (un estudio de caso)." Pp. 201-221 en Migración en el Occidente de México, editado por López Castro, G. y S. Pardo Galván. México: El Colegio de Michoacán.

Vite Pérez, M. A. 2006. "Estado, globalización y exclusión social." Política y Cultura 25: 9-26.

Walker, R. 1997. "Poverty and Social Exclusion in Europe." Pp. 48-74 en Britain divided: The growth of Social Exclusion in the 1980s and 1990s, edited by Walker, A. and C. Walker. Londres: CPAG.

Wilson, J. W. 1987. The Truly Disadvantaged. The Inner City, the Underclass and Public Policy. Chicago: The University of Chicago Press.

SIMON PEDRO IZCARA PALACIOS es Doctor en Sociología por la Universidad Complutense de Madrid y profesor de Sociología en la Universidad Autónoma de Tamaulipas (México). Algunas de sus publicaciones más recientes son: Los jornaleros tamaulipecos y el programa $\mathrm{H}-2 \mathrm{~A}$ de trabajadores huéspedes. México: Plaza y Valdés, 2010; "Abusos y condiciones de servidumbre relacionados con la implementación de los programas de trabajadores huéspedes", Frontera Norte 22 (44), 2010.

RECIBIDO: $22 / 07 / 08$

ACEPTADO: $16 / 03 / 10$

Publicado on-line: 22 de abril de 2010 